


\section{DISCLAIMER}

This report was prepared as an account of work sponsored by an agency of the United States Government. Neither the United States Government nor any agency Thereot, nor any of their employees, makes any warranty, express or implied, or assumes any legal liability or responsibility for the accuracy, completeness, or usefulness of any information, apparatus, product, or process disclosed, or represents that its use would not infringe privately owned rights. Reference herein to any specific commercial product, process, or service by trade name, trademark, manufacturer, or otherwise does not necessarily constitute or imply its endorsement, recommendation, or favoring by the United States Government or any agency thereof. The views and opinions of authors expressed herein do not necessarlly state or reflect those of the United States Government or any agency thereof. 


\section{DISCLAIMER}

Portions of this document may be illegible in electronic image products. Images are produced from the best available original document. 


\author{
Progress Report \\ Theory of Structure and Dynamics in Condensed Matter \\ and \\ Applications in Geophysies and Solar Energy
}

\begin{abstract}
SUREMARY
This has been the most successful year in the history of the program supported by this contract. Not only have the basic materials science objectives been ret, but also we have tested theory built up over the past years in thig program on the properties of rocks, and on the design of composite photothermal conversion surfaces.

The mojor topics have been:

1. Theory ot Structural Phase Transitions. (Krurhansl and Bishop)

2. Theory of Interatomic Interactions, with Application to Defect Structures and surface Complexes. (Krumbensl and Hathaway)

3. Application of the Theory of Disordered (Heterogeneous) Materials to the Elast1c Properties of Rocks, Conmerical Graphłte, and Composite Bolar Energy Absorbing Materials.
\end{abstract}

\title{
DISCUSSI ON
}

(1) Structural phase transitions oceur in many situations: Fexroelectrics, Spinodal Decomposition, and other Diffusionkess transitions, to mention a few. The dynamics of hoil these txansitions take place has been a subject of extensive investigotion in materials science, by $x$-ray, neutron and optical scattexing, particularly .

One model is the "soft mode" idea, whereby the oscjliation of the lattice in a mode whose displacement would take it to a new structural phase becomes unstablo as the temerature is varied, and the system spontaneously changes 
struature. It is this 1dea which we have sought to place on a firmer theoretical basis. The foundation was la1d in tork done by Krunhansl and $J$. R. Schrieffer, begun on sabbatic at the University of pennsylvania.

During the past (contract) year we have moved on in several directions from that work:

(1) Confirmed by computer simulation that the non-linear nature of the large amplitude displacement fields in structural phase transitions leads to new features in the structure near transitions.. That is, "microdonains" of the alternate phese appear; moreover, the statistical mechanics can be constructedin such a way as to relate these to atonistic interactions.

(2) The besis theory is related to an extensive body of literature un nonlinear waves, particulaily those called "solitons". our work has been the first to combine non-linear dynamics and statistical mechanics.

(3) For the last few years, in studtes of the dọnanics near phase transitions, a particular feature, the "central peak", has been noted experimentally as a very narrow quasi-elastic peak in neutron and Raman scattering. There are probably several alternative ways in which this may be explained, but the presence of "microdomains" provides a new possibılity.

(4) We have also applied the methods to the untsual quasi one dimensional organic conductors, such as TTF-TCNQ. In this situation the physics is somewhat different because electronic and structural transitions are coupled. We have, in collaboration with $\mathrm{w}$. J. Rice (xerox), extended our theoreticaz ideas to discuss the low temperature insulatias phase of these materials, and the novelty of the approach has drawn considerable attention. The above work has attracted general interest. It has been noted in physics Today ("Search and Discovery", February, harch 1976), and at the "European conference in Ferroelectricity", Zurich, September, 1975. Invited papers were given at the "International Conference on Low Lying Excitation and Super- 
- conductivity", San Juan, December 1975, and the Sol1d State Sciences Panel, December 1975. A number of seminars and regular papers have been presented, and the following papers have been published bs J. A, Krumhansl with coauthors listed:

"Dynamics and statiotical Mechanics of a One-Dimensional Model flamiltontan for Structural Phase Transtions", Phys, Rev. B 11, 3535 (1975) with J. R. Schrieffer.

"Rlean Field and Exact Results for structural Passe Transitions in 1-D and very Anisotropic 2-D, 3-D Systers:, wıth A. R. Bishop, Phys, Rev, B 12 2824 (1975).

"holocular Dynamics Simulation of Model For (One-Dimensional) structural Phase Transitions". Solid State Communlcations, Vol, 17, (1975) with T. R. Koehler, A. R. Bishop, and J. R, Schriefter.

"Weakly-Pinned Fröhlich-Charge-Density-Wave Condensates: A New, Nonlınear, CurrentCarryine Elementary Excitation", Physical Rev. Letters 36, 4.32 (1976) w1th A. J. Ri.ze, A. R. Blshop, and s. E. 'LruIJinger,

The following are in preprint or preparation:

"Non-L,inear Exeitations in Anstropic $X+Y$ klodels", submitted to Physics Letters, A. R. Bishop and J, F, Currte.

"Classical Particle-Like Behavior of Sine-fordon Solitons in Scattering Potentials and Applied Fieldg", submitted to phys. Rey. Letters, H. B. Fogel, S. E. Trullinger, A. R. Bishop.

"Wicroscopic Derivation of Domain E. Domany, A. R. Bishop.

It Is likely that in the solid state commanity there will be considerable general activity in this topic during the next year, and we hope to continue to be among the main contributors. During part of the contract year visiting Professor R. A. Guyer has consulted with this program.

(2) Ms. K. B. Hathawgy and J. A. Krumhansl have essentially completed the work modifying "Extended Hitickel Theory" for solid state applications, particularly surface physics and defect structures. We have possibly accomplished a more. systematic comparison of the methods used with first principle quantum ehemical 
- computations, and thereby suggested inprovements. These have been tested successfully for ionic molecules, and noble gas jnteractions. In addition Hathaway, in collaboration with D. Welch, of Brookhaven, has set up the programs for looking at defects and at the cohesive energy of higo; jesults to date axe promising. Hathenay's thesis is now completed. Publications: (J,A. Krumhansl with co-guthors)

"Extended Hückel calculation of Replusive Interactions in Noble Gases", Journal of Chemical physics, Vol. 63, No. 10 (1975), Kristi B. Hathaway.

\footnotetext{
"Potential Energy and Force Constants of a Potassium Chloride Holecule from Extended Hiickel Calculations", J. Chem, Phys. Vol. 63, No. 10, (1975) with Kristl E. Hathaway.
}

(3) For some years the principal investigator worked on the theory of randors or heterogeneous systems, particularly on the quantum mechanics and lattice vibrations of atomically disordered systens (c.f. R. J, Elliott, J. A. Krughansl, P. L. Leath, Rev. Moci. Phys. 46, 465 (1974)).

With some apology for "advertising", it is nonetheless noteworthy that theoretical work has a certain multipurpose value not always self evident froil its tmmediate appearances. Here we make the point that the methodology developed for those basic studies has now been transcribed to;

(a) "The Elasticity of Polycrystals and Rocks", E. Domany, J. E. Gubernatis, J. A. Krumhans1; Journal of Geophysical Fesearch, $\underline{80}, 4851$ (1975).

(b) "Hacroscopic Engineering properties of polycrystalime Materials" Elastic Properties", Journal of Applied Physics, 46, 1875 (2975).

(c) "Theory and Computation of Effective Electrical and Optical Properties of Composite (Photothexmal) Materials", J. A. Krumbansl, Tucson (Nov. 1975) 
$\cdot 3$

Symposium on Optical properties of Solids Relevant to Solax Energy

Converston. (Invited)

(d) "Self Consistent calculations of Elastic constants of polycrystalline Graphite", F, E. Smith, G. B. Spence, Y. E. Gubernatis, and $Y$. A. Krumhans1, Stıbmitted to "Carbon".

He believe that these applications to Eeophysics, solar energy materials, and reactor structural materials can, wfth further development contribute to better materials design methods.

\section{GENERAL}

Nunerous seminars, or contributed papers, on our work have been given by A. R. B: shop, J. A. Krumhansl, and by colleagues supported by other sourees (h. Fogel, S. F. Trullinger, J. E. Gubernatis, and E. Domany). These are not listed In detail, since the above listed publications are more to the point as an official record.

Personnel associated with J. A. Krumbansl during 1975-76, gnd receiving sone ERDA support were:

Dr. A. R. Bishop

Visiting Professor R. A. Guyer

Mis. K. Hathaway

hir . P. Muzikax

Mr. D. Wood 
COO-3161-24

WLACROSCOPIC ENGINEERING PROPERTIES OF POLYCRYSTALEINE KLATERYALS, I: GENERAL AETHODS

J. Appl. Phys. 46 1875 (1975)

$J . E$. Gubernatis and J, A. Krumhansl

c00-3161-25

STOCHASTYC THEORY OF SPIN-PHONON RELAXATI ON

Phys. Rev. B. 11 1470 (1975)

R. Pirc ancl J, A. Krumansl.

coo-3161-26

TWO POINT CORRLLATION FUNCTION FOR GENERAL FIELDS AND TERTERATURES IN THE CRITICAL REGION

Phys, Rev, B I1, 4661 (1975)

M. Combescot, $M$. Droz, and J. M. Kosterlitz

co0-316l-27

DYNAMICS WWD STATISTICAL MECHANICS OF A ONE-DIHENSIONAL MODEL HAHILTONIAN FOR STRUCTUR PL PHASE TRANSITIONS

Phys. Rev. R 11, 3535 (1975)

J, A, Krumhar.sI and J. K. Schrieffer

COD-3161-2S

ON THE EQUIVALENCE OF CONFIGURATIONAL AVERAGING FORIALISHS IN THE CPA: TWOPARTICLE PROPERTIES

J. of Phys. C.: Solid State Phys1cs 8, 3317 (1975)

A. R. Bishop

coo-316l-29

POTENTIAL ENERGY AND FORCE CONSTANTS OF A POTASSIUM CHLORIDE HOLECULE FROM EXTENDED HICKEL CALCULATIONS

5. Chen, Phys. vol. 63, no. 104313 ; 3975 )

Krist 3 B. Kathaway and James $A$. Krumhansi

C00-3161-30

EXTENDED HÜTKEI, CALCULATION OF REPULSI VE I MTSRACTIONS IN NOBLE GASES

J , Chem. Phy's. vol. 63, no. 104308 (1975)

Kristl B. Hathaway and J. A. Krumhansi

CO0O-3161-31

THE TLASTICITY OF POLYCRYSTALS AND ROCKS

J. Geophysical Research Vol. 80, No. 35 4851 (1975)

E. Donany, J. E. Gubernatis, and J.A. Krumhansl

C00-3161-32

COAHENTS ON DILUTE ISING SYSTEMS: CDUSTERING AND TRICRITICAL BEHAVIOUR Submitted to the Journal of Hagnetism

A, R, Bishop and E. Domany 
COO-3161-33

MEAN FIELD ANO FEACT RESULTS FOR STRUCTURAL PHASE TRANSITIONS IN 1-D AND IERY AFISOTROPIC 2-D, 3-D SYSTEMS

Fhys. Rev. B 12, 2824 (1975)

A. R. Bishop and J. A. Krumhansl

$600-3161-31$

MOLECULAR DYNAMICS SPIHULATION OF A MODEL FOR (ONE-DIMENSIONAL) STRUCTURAL PHASE TRANSI TIONS

Solid State Communications, Vol. 17, 1515 (1975)

T. R. Koehier, A. R. Bishop, J. A. Krumhansi, and d. R. Schrieffer

COO-3161-35

ABSENCE OF LOCALIZATEON IN THE COHERENT POTENTIAL APPROXIMATION: THE ONEDIMENSIONAL LIAIIT

Solid State Communications, vol, 17, 1405 (1975)

A. R. Bishop

$\operatorname{co0}-3161-36$

MICROSCOPTC DERIVATION OF DOMAIN TVALLS

Sublitted to the Journal on Ferroelectrics and presented at the Puerto Rico Conference E. Domany, A. R. Bishop and J. A. Krumhansl

CO0-3161-37

WEAKEY-PINNED FFOHLICH-CHARGE-DENSITY-WAVE CONDENSATES: A NEW, NOFLINEAR, CIRRENT-CARRYING ELEMENTARY EXCI TATI ON

Physical Rev. Letters 36,432 (1976)

M. J. Rice, A. R. Bishō, J. A. Krumhansl and S. E. Trullingex

CoO-3161-38

NON-LINEAR EXCITATIONS IN ANISTROPIC $X-Y$ MODELS

Submitted to Physics Letters

A. R. Bishop and J. F. Currie

COO-316I-39

CLASSICAL PARTICLE-LIKE BEHAVIOR OF SINE-GORDON SOLITONS IN SCATTERING POTENTIALS AND APPLIED FIELDS

Submitted to Phys. Rev. Letters

A. B. Fobel, S. E. Trullingex, A. R. Btshop, and J. A, Krumhansi 


\section{PERSONEL ACTI YITIES}

The principal investigator, J. A. Krumansl, devoted $25 \%$ of his time at Cornell to work on this project during the academic tersm 1975-76. Dr. A. Błshop wı11 continue until september 1976, and a new postdoctoral associate hill succeed him. ils. K. Hatharay will complete her Ph.D. 1n June 1976. Two new research assistants Mir. P. Muzikar and idr. D. Wood have recejved partial support for exploratory work on photothermal materials. Visiting professor k. A. Guyer (lniversity of Massachusetts) is consulting with us on the structural phase transition work, 